Erin K. Kross

\title{
Do physicians' beliefs influence treatment options at the end of life?
}

Received: 13 July 2012

Accepted: 21 July 2012

Published online: 11 August 2012

(C) Copyright jointly held by Springer and ESICM 2012

This editorial refers to the article available

at: doi:10.1007/s00134-012-2671-4.

\section{E. K. Kross $(-)$}

Division of Pulmonary and Critical Care Medicine,

Harborview Medical Center, University of Washington,

Box 359762, 325 Ninth Avenue, Seattle, WA 98104, USA

e-mail: ekross@u.washington.edu

Tel.: +1-206-7444649

Fax: +1-206-7448584 an option. They found that physicians who believed more strongly that life support should be withdrawn were more likely to present comfort care as an option. Interestingly, severity of illness and the number of days in the intensive care unit (ICU) prior to the family conference were not associated with the presentation of comfort care. When comfort care was presented, there was a positive association between the strength of the physician's belief that life support should be withdrawn and the number of unique benefits of comfort care that were presented to surrogates.

These findings - the fact that comfort care was not presented as an option in almost half of the family conferences for this cohort with high mortality and the fact that whether or not comfort care was presented as an option was associated with the strength of the physician's belief that life support should be withdrawn-raise questions about the process and quality of shared decision-making in the ICU. Inadequate communication is a commonly identified barrier to surrogate decision-making in the ICU [2-4], and this study raises the possibility that some of the inadequate communication experienced by surrogate decision-makers may be directly related to physicians' personal beliefs and values. The beliefs of individual clinicians vary widely, particularly when considering what constitutes appropriate care for critically ill patients [5]. If physicians' beliefs and values are influencing which options they present to surrogate decision-makers, specifically limiting or omitting options that are not in line with the physician's beliefs, surrogate decision-makers might not be fully informed for participation in shared decision-making. This may ultimately lead to treatment plans that do not match the values and preferences of the patient at the end of life, which should be our goal.

It would be interesting to further examine what specific factors are associated with physicians' beliefs about whether life support should be foregone. There may be specific demographic characteristics and clinical or 
training experiences that influence physicians' beliefs. It is also possible that physicians' emotional responses to death could affect both their belief about whether life support should be foregone and whether they choose to present comfort care as an option. Physicians often report having strong emotional reactions to patients' deaths; this is particularly true when physicians have had longer-term relationships with patients, but also true even for shortterm relationships [6]. These emotional reactions, and the stress of caring for dying patients, might influence physicians' beliefs and behaviors. These studies suggest that it is important for clinicians to be aware of their own beliefs and biases when engaging in conversations about end-oflife treatment options with surrogate decision-makers and to identify ways to ensure these beliefs and biases do not interfere with the delivery of patient-centered care.

While this study focuses on physicians' beliefs, it is also important to consider the beliefs of other members of the multidisciplinary ICU team. Specifically, it would be interesting to know whether the strength of nurses' beliefs that life support should be withheld or withdrawn is associated with whether or not comfort care is presented to surrogates as an option. Nurses may have unique views and experiences which influence their own beliefs about care at the end of life, and they have their own emotional responses to death of a patient $[7,8]$. For ICU nurses, both caring for dying patients and the number of decisions to forego life-sustaining treatments are associated with increased burnout [9], which may also influence nurses' beliefs and behavior. With an increasing focus on the importance of collaboration between nurses and physicians in the ICU [5, 10-13], consideration of the perspectives of other members of the multidisciplinary team and how those perspectives affect communication with family members and the treatment choices presented to surrogate decision-makers will be important.

This study has some important limitations, including the fact that the authors do not have information about patient preferences. It is possible that comfort care was not presented as an option because it was known that this treatment would not be consistent with the goals and preferences of the patient. However, it is very unlikely that this was the reason that comfort care was not presented as an option the majority of the time, particularly because of the strong association found with physician beliefs.

This is an important piece of work that begins to explore the reasons why comfort care is not always presented as a treatment option to surrogates of critically ill patients, and suggests that physicians' personal beliefs influence the treatment options that are presented at the end of life. Future work should explore the consequences of not presenting this treatment option for patients and their surrogate decision-makers and the best methods to ensure that shared decision-making about end-of-life care fully incorporates patients' values, goals, and preferences.

\section{References}

1. Schenker Y, Tiver G, Hong SY, White D (2012) Association between physicians' beliefs and the option of comfort care for critically ill patients. Intensive Care Med. doi: 10.1007/s00134-012-2671-4

2. Abbott KH, Sago JG, Breen CM (2001) Families looking back: one year after discussion of withdrawal of withholding of life-sustaining treatments from hospitalized patients. Nurs Res 50:105-115

3. Azoulay E, Chevret S, Leleu G, Pochard F, Barboteu M, Adrie C, Canoui P, Le Gall JR, Schlemmer B (2000) Half the families of intensive care unit patients experience inadequate communication with physicians. Crit Care Med 28:3044-3049

4. White DB, Braddock CH, Bereknyei S, Curtis JR (2007) Toward shared decision making at the end of life in intensive care units: opportunities for improvement. Arch Intern Med 167:461-467
5. Piers RD, Azoulay E, Ricou B, Ganz FD, Decruyenaere J, Max A, Michalsen A, Maia PA, Owczuk R, Rubulotta F, Depuydt P, Meert AP, Reyners AK, Aquilina A, Bekaert M, Van den Noortgate NJ, Schrauwen WJ, Benoit DD, Esicm (2011) Perceptions of appropriateness of care among European and Israeli intensive care unit nurses and physicians. JAMA 306:2694-2703

6. Redinbaugh EM, Sullivan AM, Block SD, Gadmer NM, Lakoma M, Mitchell AM, Seltzer D, Wolford J, Arnold RM (2003) Doctors' emotional reactions to recent death of a patient: cross sectional study of hospital doctors. BMJ 327:185

7. Yu HU, Chan S (2010) Nurses' response to death and dying in an intensive care unit: a qualitative study. J Clin Nurs 19:1167-1169

8. Shorter M, Stayt LC (2010) Critical care nurses' experiences of grief in an adult intensive care unit. J Adv Nurs 66:159-167
9. Poncet MC, Toullic P, Papazian L, Kentish-Barnes N, Timsit JF, Pochard F, Chevret S, Schlemmer B, Azoulay E (2007) Burnout syndrome in critical care nursing staff. Am J Respir Crit Care Med 175:698-704

10. Baggs JG, Schmitt MH, Mushlin AI, Eldredge DH, Oakes D, Hutson AD (1997) Nurse-physician collaboration and satisfaction with the decisionmaking process in three critical care units. Am J Crit Care 6:393-399

11. Baggs JG, Schmitt MH, Mushlin AI, Mitchell PH, Eldredge DH, Oakes D, Hutson AD (1999) Association between nurse-physician collaboration and patient outcomes in three intensive care units. Crit Care Med 27:1991-1998

12. Manojlovich M, DeCicco B (2007) Healthy work environments, nursephysician communication, and patients' outcomes. Am J Crit Care 16:536-543

13. McGrail KA, Morse DS, Glessner T, Gardner K (2009) "What is found there": qualitative analysis of physician-nurse collaboration stories. J Gen Intern Med 24:198-204 